\title{
Objetivos em perspectiva
}

A ABPol inicia o ano de 2002, quando completará seus 14 anos de vida, com o mesmo espírito que vem norteando seus passos desde a sua fundação: promover a disseminação do conhecimento sobre polímeros por toda a sociedade, a conjunção dos interesses acadêmicos, corporativos e de entidades de pesquisa do ramo dos polímeros e a integração de todos os profissionais envolvidos com a ciência e o negócio dos polímeros no Brasil. A composição da $7^{\text {a }}$ Diretoria eleita da ABPol que tomou posse no dia 15/11/2001 em GramadoRS no encerramento do $6^{\circ} \mathrm{CBPol}$

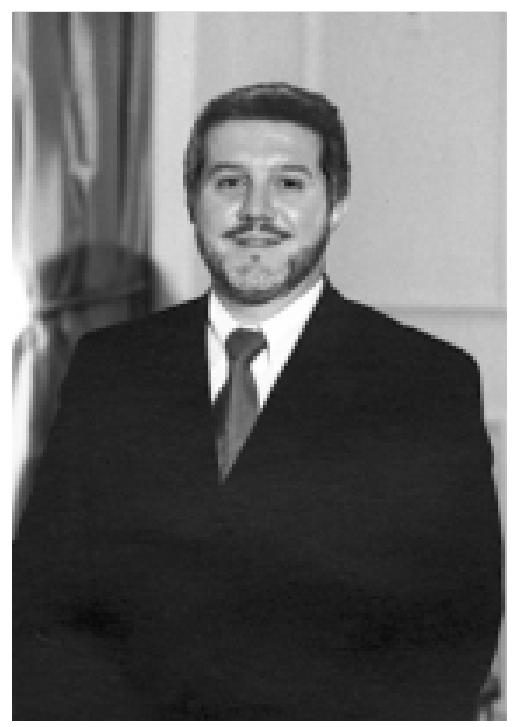

sem dúvida, manter a linha de ação adotada e reforçar as posições já conquistadas nos últimos 14 anos, mas também e principalmente, tornar-se uma associação de maior envergadura, com um leque muito mais amplo e diversificado de associados e maior presença geográfica. Uma análise crítica feita sobre o nosso quadro atual de associados revela alta concentração no meio acadêmico/P\&D, na 1 a $/ 2^{\mathrm{a}}$ geração petroquímica (refino e síntese) e no Estado de São Paulo. O desafio à nossa frente é atrair mais sócios dos segmentos de transforpara sua gestão ao longo de 2002 e 2003, reflete com fidelidade os objetivos da associação ao apresentar um equilíbrio harmônico entre representantes da iniciativa privada, do meio acadêmico e de entidades governamentais de $\mathrm{P} \& \mathrm{D}$.

Em retrospectiva, por seus quase 14 anos de existência, a ABPol demonstrou competência inequívoca ao se consolidar, através da organização dos Congressos Brasileiros de Polímeros, como um dos mais eficientes canais para a apresentação de trabalhos científicos sobre polímeros e ao conseguir indexar sua Revista - "Polímeros: Ciência e Tecnologia" no Chemical Abstracts e RAPRA e se firmar globalmente como um dos meios mais confiáveis para a divulgação do conhecimento na área de polímeros. A ABPol também mostrou excelente desenvoltura ao se articular com outras associações correlatas (por exemplo, a SPE Society of Plastics Engineers) para a organização de eventos conjuntos e resultados significativos na realização de conferências, simpósios e treinamentos aplicados "in house" dirigidos às empresas de produção, transformação e testes de polímeros.

Quais serão então os objetivos da ABPol em perspectiva, para o futuro, para os próximos 14 anos, por exemplo? A visão de longo prazo da ABPol contempla, mação/montagem, equipamentos e controle/testes de polímeros, hoje praticamente ausentes de nosso portifólio e aumentar o número de associados nos Estados da região sudeste além de São Paulo e nas regiões Sul, Nordeste, Norte e Centro-Oeste do Brasil. Os meios para atingir esses fins estão em democrático debate no seio da ABPol, mas alguns pontos, em princípio, parecem obter convergência de opiniões: implantar uma adequada e consistente estratégia de comunicação com os públicos-alvos definidos e a criação/alavancagem de novas/atuais Regionais são fatores críticos para o cumprimento da missão da ABPol.

As discussões sobre nossa Revista e todas as decisões envolvendo qualquer meio de divulgação e promoção na nossa estratégia de comunicação serão muito importantes para o futuro da ABPol. Expresso aqui o meu convite para que todos os leitores participem e contribuam com a Diretoria da ABPol e o Comitê Editorial da Revista com suas idéias, opiniões e pontos de vista através de carta, fax ou, preferencialmente, correio eletrônico endereçados à Redação. Obrigado!

Domingos J afelice Presidente da ABPol 